
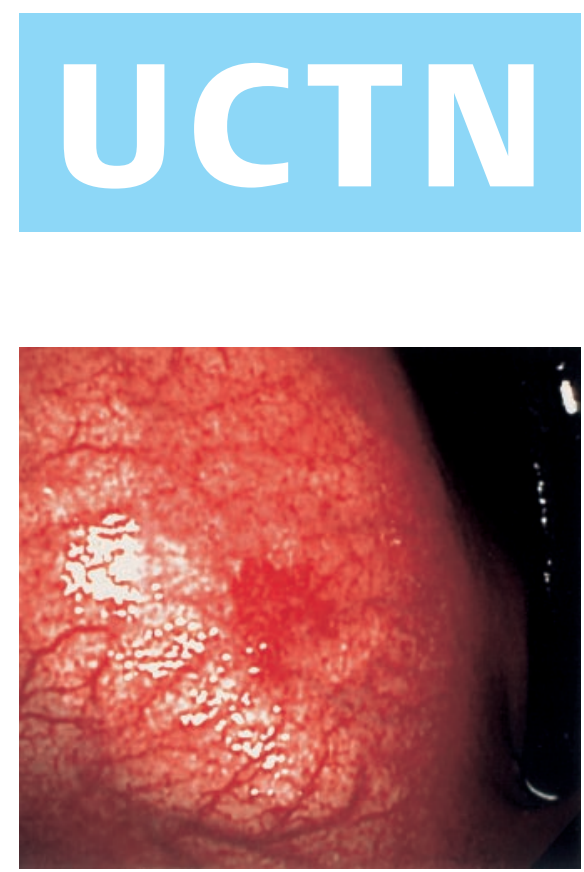

Figure 1 Findings at ordinary endoscopy suggested angiodysplasia of the stomach.

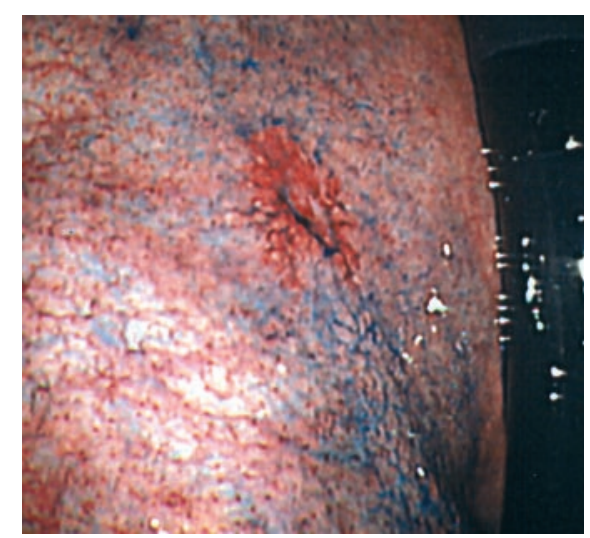

Figure 2 View at magnifying endoscopy with dye-spraying suggesting gastric cancer.

A 51-year-old Japanese man came to medical attention because of a routine stomach check-up. On endoscopy, angiodysplasia of the posterior wall of the cardia of the stomach was suspected (Figure $\mathbf{1}$ ), and magnifying endoscopy with dyespraying was done. A shallow recess with a small erosion in the center was ob-

\title{
Gastric Cancer Mimicking Angiodysplasia
}

served and a biopsy was therefore taken (Figure 2). The histological findings suggested well-differentiated tubular adenocarcinoma. Endoscopic ultrasonography showed only a thickening of the mucosal layer. Based on these findings, endoscopic mucosal resection (EMR) was carried out. The lesion was removed en bloc. The resected tumor was $9 \times 8 \mathrm{~mm}$ and histological examination revealed well-differentiated tubular adenocarcinoma limited to the mucosal layer.

Gastroduodenal angiodysplasia has been diagnosed by endoscopy [1]. Because of the low diagnostic yield and risk of provoking hemorrhage, endoscopic mucosal biopsies for diagnostic purposes are not generally recommended. In the case presented here there were no endoscopic features suggestive of gastric cancer and the lesion appeared to be angiodysplasia. However, since endoscopy revealed very slight irregularity in the vascular lesion and a visible vascular pattern based atrophic gastritis, we considered that magnifying endoscopy with dye spraying was necessary to confirm the diagnosis. This revealed several features suggestive of gastric cancer.

It is probable that some gastric cancers have not been examined carefully, and have been endoscopically misdiagnosed as angiodysplasia. The differential diagnosis between gastric cancer and angiodysplasia is not very difficult for endoscopists. If it is difficult to make a diagnosis on ordinary endoscopy, chromoscopy should be done and biopsy taken during endoscopy [2]. These procedures can make it possible to endoscopically diagnose and treat early gastric cancer mimicking angiodysplasia.

\section{K. Kume ${ }^{1}$, I. Yoshikawa ${ }^{1}$, T. Myojo ${ }^{2}$, M. Otsuki ${ }^{1}$}

${ }^{1}$ Third Department of Internal Medicine, University of Occupational and Environmental Health, School of Medicine, Kitakyushu, Japan

${ }^{2}$ Internal Medicine, Nogata Central Hospital, Kitakyushu, Japan.

\section{References}

${ }^{1}$ Gunnlaugsson O. Angiodysplasia of the stomach and duodenum. Gastrointest Endosc 1985; 31: 251 - 254

2 Lambert R, Rey JF. Endoscopy and early neoplasia: better not the best. Endoscopy $2001 ; 33: 348-352$

\section{Corresponding Author}

\section{Otsuki, M.D., Ph.D.}

Third Department of Internal Medicine, University of Occupational and Environmental Health, Japan, School of Medicine

1-1, Iseigaoka, Yahatanishi-ku

Kitakyushu 807-8555

Japan

Fax: + 81-93-692-0107

E-mail: mac-otsk@med.uoeh-u.ac.jp 